\title{
Alfabetizadoras da EJA: entre Memórias, Saberes e Viveres (1940-1960)
}

The EJA Literacy Teachers: between Memories, Knowledge and Life (1940-1960)

Alfabetizadoras de la EJA: entre los Recuerdos, el Conocimiento y las Vivencias (1940-1960)

\section{Rita TAVAREs De MELlo ${ }^{1}$; Sônia MARIA dos SANTOS ${ }^{2}$}

\section{Resumo}

Este trabalho apresenta parte da pesquisa História, Memória e Vivências: A EJA no Norte de Minas Gerais 1940-1960, investigando a historiografia local, reconstituindo a história e memória dos saberes e práticas de professoras. Procurou-se compreender como procediam na alfabetização dos adultos, considerando as dificuldades daquela realidade para o saber sobre sua profissão. Situado no campo da Educação de Jovens e Adultos, focado na história oral temática. Os resultados da pesquisa apontam o modo como as trajetórias dessas educadoras foram construídas, marcadas pela coibição política e pedagógica em uma época em que o sertão do Norte de Minas Gerais era considerado uma região de "resistência habitual ao analfabetismo". A presente pesquisa conduziu à percepção de que as professoras alfabetizadoras não somente criaram alternativas de trabalho ou mesmo aprenderam com suas próprias experiências, mas, se inscreveram em uma tradição, resgatando laços com a EJA, como tributárias, continuadoras e recriadoras de uma tradição.

Palavras-Chave: História. Memória. Saberes e Práticas. EJA no Norte de Minas Gerais.

\footnotetext{
${ }^{1}$ Doutora em Educação (História e Historiografia da Educação) pela Universidade Federal de Uberlândia. Professora de Educação de Jovens e Adultos do Curso de Pedagogia da Universidade Estadual de Montes Claros. E-mails: ritatavares.mello@gmail.com

${ }^{2}$ Doutora em Educação (História, Política, Sociedade) pela Pontifícia Universidade Católica de São Paulo, com estágio de pós-doutorado realizado na Universidade Federal de Minas Gerais. Professora Titular da Faculdade de Educação da Universidade Federal de Uberlândia. E-mails: soniaufu@gmail.com
} 


\title{
Resumen
}

Este artículo presenta parte de la investigación Historia, Memoria y Experiencias: la educación de adultos en el Norte de Minas Gerais 1940-1960, la investigación de la historia local, que describe la historia y Memoria de conocimientos y prácticas de los profesores. Se buscó entender cómo sucedió la alfabetización de adultos, teniendo en cuenta las dificultades de aquella realidad para el saber acerca de tu profesion. Situado en el campo de la educación de jóvenes y adultos, se centró en la historia del tema oral. Los resultados de la investigación muestran cómo las trayectorias de estos educadores fueron construidas, marcadas por la moderación política y pedagógica en un momento en el que el la región "sertão" del Norte de Minas Gerais era considerada una región de "resistencia habitual a el analfabetismo. Esta investigación dio lugar a la percepción de que los maestros alfabetizadores no sólo crearon alternativas de trabajo o incluso aprendieron de su propias experiencias, pero se inscribieron en una tradición, restaurando los lazos con la EJA, como contribuidoras de impuestos, continuadoras y recriadoras de una tradición.

Palabras clave: Historia. Memoria. Conocimientos y prácticas. EJA en el norte de Minas Gerais.

\begin{abstract}
This work presents part of the History research, Memory and Experiences: The "EJA" in the North of Minas Gerais 1940-1960, investigating local historiography, retracing the history and memory of the knowledge and practices of teachers. It sought to understand how they preceded in the adult literacy, considering the difficulty of that reality to the knowledge about their profession. Situated in the Field of Youth and Adult Education, focused on thematic oral history. The research results point to the way such educator's trajectories were built, marked by the policy and teaching restraint in a time when the "Sertão" of northern Minas Gerais was considered a region of "habitual illiteracy resistance". The present research led to the perception that literacy teachers not only created working alternatives or even learned from their own experiences, but enrolled in a tradition, restoring ties with the "EJA", as tributaries, continuers and recreatives of a tradition.
\end{abstract}

Keywords: History. Memory. Knowledge and practices. "EJA" in the North of Minas Gerais. 
O presente trabalho sistematiza parte da pesquisa intitulada "HISTÓRIA, MEMÓRIA E VIVÊNCIAS: A EJA NO NORTE DE MINAS GERAIS - (1940-1960)”, trata-se, portanto, de uma pesquisa que se situa no campo da educação de jovens e adultos, cujo foco é a história oral temática. Diante desse campo de investigação inúmeras questões se colocam e visam esclarecer e revelar a história da alfabetização como, por exemplo, o que significava, naquela época (1940-1960), ser alfabetizadora da EJA?

Por meio deste estudo, buscou-se revelar quem foram as professoras que atuaram no processo de alfabetização, os lugares e as condições em que alfabetizavam, o que as levou à profissão de professoras alfabetizadoras, qual era o nível de escolaridade, a origem (pertencimento) social e como eram vistas na (e pela) sociedade. Também, procurou-se evidenciar, entre outros aspectos quais eram as concepções teórico-práticas construídas em torno do ato de ensinar e aprender, bem como os materiais didáticos utilizados, e o porquê de usar tais materiais. Em relação às instruções para o exercício da profissão de alfabetizadoras de adultos, coube questionar quem encaminhava essas instruções e qual a influência sociocultural das escolas para o Norte de Minas Gerais.

A partir dos questionamentos elencados, esta pesquisa teve como pressuposto investigar a historiografia local, reconstituindo a história e memória dos saberes e práticas de sete professoras alfabetizadoras, analisando o contexto, o lugar, o espaço, bem como as dificuldades, problemas, resistências e, principalmente o significado do ofício de ser alfabetizadoras de adultos no período de 1940 a 1960. Como objetivos específicos este estudo buscou delimitar, inicialmente o período histórico, identificando, descrevendo e analisando os saberes e práticas mobilizadas pelas alfabetizadoras no processo ensino-aprendizagem dos adultos. Também os modos como essas alfabetizadoras utilizavam o método didático na condução da atividade de alfabetizar, tendo em vista a necessidade de aquisição do código alfabético e do desenvolvimento das habilidades de leitura e compreensão dos textos. Além disso, compreender como as alfabetizadoras nortemineiras procediam na alfabetização dos adultos, considerando as dificuldades daquela realidade para o saber sobre sua profissão e sobre o saber fazer profissional.

De tal modo, este estudo buscou privilegiar a história de homens e mulheres comuns, porque esses também fazem parte da história, e ainda em documentos não convencionais encontrar os vestígios dessa história. Contudo, as fontes oficiais não foram descartadas, ao contrário, estabeleceram um elo com as não-convencionais, e igualmente foram criticadas e analisadas.

\section{Percurso Metodológico: a História Oral}

Como recurso metodológico a história oral temática, que na contemporaneidade pode ser usada para se estudar a vida de pessoas, de grupos ou de comunidades, como possibilidade de acessar o passado, foi utilizada como forma de resgatar as memórias das alfabetizadoras selecionadas para esta pesquisa.

No que se refere às fontes orais, essas assumem espaços e significados diferenciados, pela possibilidade de se reportar à memória coletiva pela via das experiências individuais, em uma época e no âmbito de um determinado grupo social. Assim, no contexto desta pesquisa, a história oral se constitui como uma rica possibilidade. Todavia, conforme Le Goff (2003), ao buscar as experiências vividas por sujeitos concretos, pode-se considerar que a afetividade, o 
desejo, a inibição e a censura exercem manipulações conscientes ou inconscientes, sobre a sua memória individual, tanto no esquecimento, como na recordação. Entendendo também que, muito do que é verbalizado ou integrado à oralidade, como gestos, lágrimas, risos, silêncios, pausas, interjeições ou mesmo as expressões faciais que, na maioria das vezes, não têm registros verbais garantidos em gravações, podem integrar os discursos que devem ser trabalhados para dar dimensão física ao que foi expresso em uma entrevista de história oral. A consideração da entrevista além do que é registrado em palavras é um dos desafios da história oral (MEIHY e HOLANDA, 2010). Portelli ressalta que:

A entrevista não é um ato de extrair informações, e sim o abrir-se de um espaço de narração, um espaço compartilhado de narração, em que a presença do historiador oferece ao entrevistado alguém que está ali para escutá-lo, coisa que não lhe ocorre com frequiência (2010, p. 04).

Entendemos, então, que toda pesquisa com entrevista é um processo social, uma interação, uma troca de ideias e significados, onde o respeito e a fidelidade devem ser imperativos ao ouvir a narrativa do outro, processo em que várias realidades e percepções são exploradas e desenvolvidas. Oliveira refere-se, assim, à História Oral:

A história oral recupera aspectos individuais de cada sujeito, mas ao mesmo tempo ativa uma memória coletiva, pois, à medida que cada indivíduo conta a sua história, esta se mostra envolta em um contexto sócio-histórico que deve ser considerado. Portanto, apesar de a escolha do método se justificar pelo enfoque no sujeito, a análise dos relatos leva em consideração, como já foi abordado anteriormente, as questões sociais nele presentes (2005, p. 94).

Conhecer os sujeitos cujas trajetórias profissionais e de vida foram marcadas pelo envolvimento na educação de jovens e adultos é relevante para compreensão do objeto deste estudo. As opções pessoais, os percursos de vida, os sonhos, as rupturas, as experiências, as descobertas, os modos de aprender e ensinar, estão registrados em forma de narrativas, as quais constituem uma fonte rica de reflexão sobre os processos de configuração que permeiam a EJA na contemporaneidade. Reconstituir a memória dessas educadoras, identificando suas representações sobre o ato de alfabetizar adultos em um período remoto, constituiu o caminho para a compreensão de como a educação de jovens e adultos foi ganhando a configuração que hoje conhecemos; processo esse marcado por uma construção permanente, em que se delineiam lutas, rupturas, avanços e continuidades.

Neste estudo, na fundamentação teórica, adotou-se o campo da História Cultural que, de acordo com a Escola dos Annales, concebe "uma etapa decisiva nesse processo de consolidação da história cultural e da emergência daquilo que passaria a ser nomeada como Nova História Cultural" (CAVALCANTE JUNIOR; SILVA; COSTA, 2010, p.48), "para designar toda historiografia que se tem voltado para o estudo da dimensão cultural de uma determinada sociedade historicamente localizada" (BARROS, 2005, p.2). 
A historiografia tem sido compreendida como uma das possibilidades de investigação, e também pelos dilemas, controvérsias e conflitos. A História é um campo que nos possibilita montar mosaicos construídos com muitas "histórias", escritas em espaço não-homogêneo, perpassado por diferentes tendências e orientado por uma diversidade de conceitos. Segundo Inácio Filho e Abreu,

A riqueza em trabalhar dentro do campo de pesquisa e estudos da História da Educação é perceber como a Educação e a História se entrelaçam como dois campos distintos, mas que se completam. Acompanhar em cada leitura, em cada nova documentação, como as contradições sociais e históricas se evidenciam na Educação é esclarecedor e ao mesmo tempo instigante (2006, p.133).

Compreender essas diversas abordagens fez parte da tarefa das pesquisadoras e constituiu-se como condição para o ofício de historiar a realidade, uma vez que, conforme os autores acima, História e Educação são dois campos que se imbricam, e podemos considerar que um encontra sustentação no outro. A historiografia tradicional abriu-se para acolher outras possibilidades de compreensão da realidade, que não é apenas política, mas, sobretudo social, visto que ser refere à dimensão humana. Para Araújo, Ribeiro e Souza (2011), a historiografia tem sua etimologia explicada pela junção de dois termos: história e escrita, ou seja, trata-se da "escrita da história", podendo ser distintos dois sentidos fundamentais:

o primeiro seria os processos de busca de evidências empíricas, de sua análise e de sua interpretação compreendidos como historiografia, uma vez que envolvem uma teoria e uma metodologia em vista da própria escrita da história" e o segundo trata-se de uma investigação sobre a história da escrita da história, uma vez que ela é sempre reescrita, é possível localizar seus diversos contornos interpretativos, suas aspirações, suas temáticas eleitas, suas ideologias (ARAÚJO, RIBEIRO e SOUZA, 2011, p.97).

Alguns pesquisadores, dentre eles Santos (2001), corroboram que o número de estudos científicos na história da educação e da historiografia brasileira cresceu expressivamente nos últimos anos. Os estudos começaram a desvelar a história do sujeito que vive no anonimato e não só aquele que está nas fontes oficiais escritas pelas elites intelectuais.

Genericamente, podemos afirmar que História Cultural é um campo de trabalho que ganhou visibilidade a partir das últimas décadas do século $\mathrm{XX}$, e tem sido utilizada para fazer referência a uma historiografia que tem por foco a dimensão cultural no estudo de uma determinada sociedade (um deslocamento da história social da cultura para a história cultural da sociedade). Recentemente, os historiadores culturais entendem que o termo cultura não pode estar associado apenas às artes e aos valores da elite. Por esta concepção, consideram a cultura numa perspectiva antropológica, que inclui os fazeres e práticas cotidianas de todos os grupos sociais (PESAVENTO, 2003, p. 15). 
Convém ressaltar que a preocupação em selecionar e analisar as narrativas das professoras alfabetizadoras pesquisadas não se deteve no fato dessas narrativas serem consideradas pelos cartesianos como subjetivas e nada confiáveis, mas na possibilidade de ouvir e registrar os saberes e práticas das entrevistadas. Assim, foi importante trazer à tona as vivências e experiências que antes pertenciam ao anonimato, também poder abranger uma parte da história da EJA que está presente em seu habitus, nos seus esquemas de pensamento e, mesmo após tantos anos, ainda é visto por elas com a mesma importância que teve no período em que atuaram.

A memória parece um "pandemônio", as lembranças estão todas lá e a partir do momento em que alguém se dispõe a ouvir, elas surgem naturalmente, e se surgem muitas vezes desencontradas é porque também para as lembranças existem os "interesses", cabe ao pesquisador, de acordo com Bosi (2004), interpretar tanto a lembrança quanto o esquecimento. Inicialmente desencontradas, parecendo impossível recompô-las integralmente, a memória pouco a pouco vai compondo o mosaico e vai se podendo analisar cada fragmento de lembrança, tentando ajustar cada pequeno pedaço que após tantos anos já não se mostra tão completo, mas mesmo assim importante. Juntar cada peça desse mosaico constituiu-se numa grande tarefa de trazer o passado para o presente, ou seja, ao lembrar, ao reviver o passado, o presente vai se fazendo novo, de tal modo, tempo e espaço vão se (con)fundindo, criando um entrelaçamento na memória, o que não foi lembrado fielmente teve seu valor na reconstrução desse tempo e desse espaço.

O caráter livre, espontâneo, quase onírico da memória é, segundo Halbwachs (2004), excepcional. Na maior parte das vezes, lembrar não é reviver, mas refazer, reconstruir, repensar, com imagens e ideias de hoje, as experiências do passado, "memória não é sonho, é trabalho" (BOSI, 2004). A lembrança é uma imagem construída pelos materiais que estão, agora, à nossa disposição, no conjunto de representações que povoam nossa consciência atual.

Passível de ser lido como memória local, o Jornal Gazeta do Norte também foi utilizado como fonte, visto que os acontecimentos relatados pelo periódico oferecem pistas úteis para a caracterização da esfera educacional da sociedade montes-clarense da época, em determinado momento. Embora a imprensa escrita possa ser analisada segundo óticas distintas, não se pode negar que, conforme Nóvoa (1997), trata-se de um corpus documental que, como poucos, traduz com abundância:

[...] os debates, os anseios, as desilusões e as utopias que têm marcado o projeto educativo nos últimos dois séculos. Todos os Atores estão presentes nos jornais e nas revistas: os alunos, os professores, os pais, os políticos, as comunidades [...] As suas páginas revelam, quase sempre - a quente, as questões essenciais que atravessaram o campo educativo numa determinada época (NÓVOA, 1997, p. 30).

A imprensa, ao realizar essa operação "não natural" de criar lugares da memória, possibilita travar um diálogo com um determinado tempo, com modos de vida, com sujeitos que organizavam e reorganizavam suas vidas de forma distinta da contemporaneidade, porém com ações que ainda interferem diretamente no cotidiano, na atualidade. A imprensa, dessa forma, pensando-a como filtro, faz uma "seleção", ao optar em publicar sobre este político em 
detrimento daquele, ao relembrar aquele fato da educação e não este; enfim, escolhe quais os valores que podem ou não virar memória. Entende-se memória como elemento capaz de revitalizar a compreensão do passado e, pensando nessa revitalização, buscamos entender como as alfabetizadoras identificavam, descreviam e analisavam seus saberes e suas práticas no oficio de alfabetizar adultos.

Em uma palestra ocorrida no Brasil, em maio de 2007, Portelli afirmou que "atacar a memória é atacar a identidade de instituições". Assim, neste estudo, analisar o jornal Gazeta do Norte foi também um exercício de provocar as instituições mencionadas pela imprensa, colocando em movimento a trajetória e a função dessa imprensa para o norte de Minas. Esse exercício propiciou o entendimento de como a memória foi construída pela imprensa local e de como, ao deixar seus resquícios, vai construindo outras memórias.

Trabalhar a imprensa como fonte, parte do entendimento de que essa possibilita um diálogo direto com o processo histórico em questão, e traz à tona fragmentos de uma memória materializada pelo jornal. Na historiografia inúmeros trabalhos se destacam pela abordagem e questionamentos que constroem ou desconstroem o conceito de memória, como no trabalho de Le Goff (2003), para quem a memória significa apropriação de imagens e textos, fenômeno individual e psicológico, totalmente ligado ao tempo e à sua apropriação. Já Hobsbawm (1998) assevera que "passado é dimensão permanente da consciência humana" e é também "seleção do que é ou será capaz de ser lembrado" (p.231).

Para o historiador, o acervo jornalístico se revela como uma possibilidade de pesquisa, desde o conteúdo das manchetes até a disposição dessas nas páginas dos periódicos. Portanto, indagar os jornais vai além da simples leitura de suas páginas, ou das informações que as compõem. O trabalho com essa fonte possibilita entender os interesses que são verbalizados por essa prática social e salientar a sua intervenção no cotidiano, pois, conforme Almeida (2006), "o jornal interfere e sofre interferências sociais". As "fissuras da vida" que abarcam o ir e vir da linguagem, possibilitam refletir sobre o desenvolvimento humano e, no caso deste trabalho, propicia problematizar os processos de alfabetização, analisando possíveis dificuldades ou resistências, rupturas e permanências ocorridos na educação de jovens e adultos no Norte de Minas Gerais, em meados do século XX.

No que se refere a esta pesquisa, procurou-se as motivações que levaram os jornalistas e redatores a publicarem sobre alfabetização, analfabetismo, ato de ensinar e aprender, e foram essas publicações que possibilitaram estabelecer um diálogo com o passado, fazendo emergir as relações e interesses que não estavam registrados em letras garrafais nas páginas dos periódicos. Pensando a história por meio da imprensa, podemos tomá-la como prática social constituída de linguagem própria. Para alguns autores, a imprensa não passa de um meio informativo, porém, para outros se constitui de um ir e vir de informações, práticas, de posturas e projetos. Vale ressaltar que, neste estudo, não pretendemos contar a história da imprensa, mas destacar alguns aspectos relevantes desse meio de comunicação pela contribuição que disponibiliza àqueles que se propõem utilizá-lo como fonte de pesquisa.

A imprensa, portadora e produtora de significações, possui um dos dispositivos privilegiados para forjar o sujeito, ou seja, pela necessidade de informar sobre fatos, opiniões e acontecimentos, procura engendrar uma mentalidade, se posicionando como um lugar 
estratégico de constituição do discurso. Sendo assim, ela (a imprensa) estabelece um espaço público através do seu discurso, que é social e simbólico, agindo como mediadora da cultura e da ideologia fixa normas, sentidos, organiza relações e disciplina conflitos (BASTOS, 2002, p.152). Normalmente carregada de intenções, ao incorporar e promover práticas que legitimam e privilegiam alguns acontecimentos em detrimento de outros, produz e divulga saberes que homogeneízam, modelam e disciplinam seu público alvo.

Nesse direcionamento, compete ao pesquisador fazer uma desmontagem dos textos veiculados pela imprensa, filtrando as informações, a fim de desvelar os significados, as contradições e as diferenças implícitas nas falas que produz, para que não tomemos a notícia como sendo toda a realidade, nem as opiniões emitidas como representativas de todo o imaginário. O exercício da dúvida, mais do que nunca, deve se fazer presente quando se analisa as representações do passado (NETO, 2002, p.206-207). A imprensa é, pois, o espaço da comunicação, sendo o jornal uma parcela dessa imprensa, um documento histórico singular que tem um mosaico de notícias que estampa sua característica. Ainda, conforme Neto (2002) é principalmente através da imprensa que se divulgam e se consolidam as principais representações sociais. Tendo a capacidade de formar a cultura e padronizar o povo, ela é preconizada também como veículo educativo, a responsabilidade do jornalismo na formação da opinião pública, na divulgação da informação, o acesso à diversidade de opiniões são colocados como elementos impulsionadores da civilidade, do progresso do país e da formação da nação.

Assim, para qualificar este estudo, foram utilizadas fontes impressas e documentais e, nesse sentido, o Jornal Gazeta do Norte, conforme Veloso (2008), permitiu a compreensão do passado, laçando luz sobre questões contemporâneas. As edições do Gazeta do Norte foram selecionadas conforme as abordagens referentes à educação de Jovens e adultos, nas quais buscou-se não somente entender a informação, mas também problematizar o sentido de pertencimento social das alfabetizadoras de adultos, como eram vistas na (e pela) sociedade, portanto, compreendidas como objeto de investigação.

De tal modo, foram entrevistadas sete professoras que atuaram em escolas públicas de Montes Claros como professoras alfabetizadoras de jovens e adultos nos anos de 1940 a 1960, como forma de recuperar as memórias e experiências vivenciadas por elas em sala de aula, num momento em que os desafios da educação e a necessidade de renovação das práticas eram impostas pelo regulamento do ensino e pelas novas demandas por leitura e escrita. De acordo com Santos (2001), a construção da identidade/profissionalidade de cada alfabetizadora está muito ligada ao seu ambiente familiar e cultural, por meio dos modelos e valores com os quais conviveram e se relacionaram em seu processo de escolarização e vivência profissional. As entrevistas com as professoras alfabetizadoras aconteceram por meio de um roteiro semiestruturado, tendo sido previamente explicados os motivos da pesquisa e esclarecida a intenção de desvelar suas histórias de vida, resgatando, através de seus relatos, o momento histórico (1940-1960) em que elas atuaram como alfabetizadoras de adultos. Neste estudo, no contexto das narrativas das entrevistadas, a abordagem escolhida foi a compreensão da história como memória coletiva do passado, consciência crítica do presente e premissa operatória para o futuro. 


\section{Sertão do Norte de Minas Gerais: lugar de Histórias}

O Norte de Minas é um espaço singular no contexto estadual, a maior parte dos estudos acadêmicos relaciona a região com a pobreza, a seca, o isolamento regional, o analfabetismo, a dependência dos recursos da União e do Estado. Segundo Gervaise (1975), “[...] o Norte de Minas apresenta talvez o mais espetacular dualismo do Estado, a imagem de dinamismo se superpõe a uma tradição de atraso que caracteriza a metade norte do Estado" (p.19). Outro autor que compartilha a mesma opinião é Costa, ao afirmar que:

[...] o norte de Minas, como uma região subalterna, ao emergir no cenário brasileiro evidenciando sua especificidade identitária aparece, duplamente, como uma assombração à nação e a mineiridade, ao afirmar sua condição fronteiriça como sertão, no Brasil e em Minas Gerais (2003, p.15).

A região Norte de Minas, dominada pelas oligarquias, era subjugada ao comando dos coronéis. Pereira (2002) caracteriza coronelismo como as diversas relações - lideranças - povo; lideranças - lideranças; Município - Estado - União, travadas no cotidiano e acentuadas nos períodos eleitorais. Essas relações compõem um modelo de dominação social e política. Contudo, tal dominação é limitada pelo caráter recíproco da dependência imposta pelo sistema eleitoral, que garante ao indivíduo o direito ao voto e, ao mesmo tempo, obriga o candidato a conquistá-lo pelas estratégias populares de participação política, sejam de forma submissa ou rebelada (PEREIRA, 2002)

Os jornais locais se referiam à cidade de Montes Claros como a "Princesa do Norte", o "Coração robusto do sertão", mesmo sendo rota de imigrantes nordestinos em direção a São Paulo, nas décadas de 1930 a 1960. O fato de ser um ponto de passagem incomodava as elites regionais, uma vez que não aceitavam que a imagem da cidade fosse relacionada ao problema dos retirantes nordestinos, como a pobreza e suas consequências. Esse discurso de desenvolvimento e progresso muda completamente quando, o então, presidente Juscelino Kubistchek determina a criação da SUDENE, tornando muito oportuno para a região ser identificada com o Nordeste. A partir da década de 1960, a região Norte de Minas Gerais definese como "região das secas" e do "abandono", só recebendo efetivamente recursos de incentivo a partir de 1965 (PEREIRA, 2007). O sertão permeado de diferenças, entre o limiar do bárbaro e do civilizado, está em toda parte, como já dizia Guimarães Rosa, mas o sertão mineiro, o sertão das Gerais, não estava nas Minas, assim como as Minas não estavam nas Gerais. O estado mineiro historicamente desenvolveu-se com visíveis diferenças regionais. Sempre fez distinção entre as Minas, referindo-se às regiões centrais e sul do Estado, onde as riquezas minerais prevaleciam, o setor agropecuário se expandia; e as Gerais, localizadas nos sertões, onde se concentravam os problemas das secas, da pobreza, da luta pela sobrevivência e do analfabetismo. Todo o investimento ia para as Minas, seja na área econômica, cultural, educacional, existia de fato um distanciamento, não somente geográfico, mas especialmente de abandono, ignorando as mazelas existentes nas Gerais. 
No setor educacional não foi diferente, a região era hostilizada, como demonstra um relatório datado de 1911, no início do século XX. O então secretário, Delfim Moreira da Costa Ribeiro, encaminha ao Presidente do Estado sua opinião em relação à criação das Escolas Normais e como deveria ser a educação no sertão mineiro, após a promulgação da Lei $n^{\circ} 439$ de 1906, em que o governo de Minas Gerais apresenta sua proposta para a educação atendendo ao ideário republicano, no qual a "modernidade" deveria aparecer de forma concreta aos olhos da população.

Formar o professor deve ser o primeiro cuidado de quem pretenda organizar o ensino e, como conseqüência, apparece a instituição das Escolas Normaes, tratada com verdadeiro carinho em todos os paizes civilisados. A reforma fundou na capital a Escola Normal modelo para o sexo feminino e instituiu a fiscalização equiparada. Está incompleto, no meu parecer, o ensino normal assim organizado, por que deveriam abranger ambos os sexos. A orientação nova é para confiar-se o ensino primário à mulher; essa substituição, porém, só se poderá fazer, em nosso Estado, gradativa e lentamente. Dadas as condições actuaes da inaccessibilidade dos logares e da rudeza do meio, a professora normalista não poderá, como o professor, affrontar os sertões; procurará naturalmente localizar-se na orla mais civilizada. O sertão mineiro é a resistência habitual do analphabetismo o mais grosseiro e indisciplinado e a professora não tem as condições de energia e resistência moraes para desbrava-lo. $\mathrm{O}$ ensino nessas paragens incultas merece mais amor e cuidados da administração do que da parte já quase conquistada pela iniciativa particular. Precisamos ainda do professor normalista e o meio de leva-lo ao sertão consistirá talvez em dar-lhe uma porcentagem a mais sobre os vencimentos ordinários (RIBEIRO, 1911, p. 28).

Nas palavras do secretário, "o sertão é a resistência habitual ao analfabetismo, o mais grosseiro e indisciplinado, a professora normalista não poderá afrontar os sertões”, ou seja, na opinião do secretário somente os homens seriam capazes de realizar a difícil tarefa de educar no sertão. O conteúdo do relatório deixa evidente como o norte de Minas Gerais era desamparado, excluído dos benefícios, ou porque não dizer, abandonado à própria sorte.

A partir das considerações empreendidas até aqui, certificamos que a região do Norte de Minas, em todo o seu contexto, ao longo do processo de ocupação foi marcada por uma política de exclusão, sendo em muitos casos pautada pelo assistencialismo. Nesse sentido, considerando a proposta desta pesquisa, avaliamos que as políticas educacionais pensadas para a região quase sempre estiveram atreladas a interesses políticos, em detrimento das reais necessidades de reverter o alto índice de analfabetismo da região.

\section{O Experimentado e o Vivenciado: a constituição da Alfabetizadora da EJA}

A partir das trajetórias de vida e de trabalho das professoras alfabetizadoras fomos capazes de identificar suas representações sobre o período de 1940 a 1960 a respeito da alfabetização de adultos no sertão do norte de Minas Gerais. No contexto das narrativas das professoras alfabetizadoras procuramos destacar que a abordagem escolhida para este estudo é a compreensão da história como memória coletiva do passado, consciência crítica do presente e premissa operatória para o futuro (SOUZA, 2000). 
No decorrer desta pesquisa os sujeitos com os quais nos deparamos são mulheres, casadas, solteiras, viúvas, mães, que, enfim, por alguma razão se tornaram professoras alfabetizadoras. Fontana (2003) analisa a questão do gênero na constituição da professora e o importante papel mediador do trabalho no processo de constituição da singularidade na trama das relações sociais, em que a esposa, a filha, a mãe e a professora se entrelaçam, modulando os modos de ser e de dizer de cada professora:

Diferentes modos de relação da mulher com suas atividades ganham centralidade. Para a Dona de casa, a família é o catalisador de suas atividades e os papéis de esposa e mãe definem os contornos do seu modo de ser mulher e de reconhecerem-se como sujeitos. A atividade profissional é espaço de relações e lugares sociais, que passam a ser vivido pela mulher. Esses lugares sociais implicam modos de ação e preocupações distintas das práticas familiares, passando a dividir com estas a definição de prioridades e sua própria motivação frente a elas. A atividade profissional não apaga os papéis de esposa, Dona de casa, mãe, filha. Acrescenta-se a eles, [...] mas rompe com a relação de continuidade e harmonia frente a eles. [...] a esposa, a Dona de casa, a filha, a futura professora, a estudante. [...] coexistem e enfrentam-se numa professora, reorganizando e mobilizando convicções, crenças e valores e também o próprio modo de viver cada um desses papéis configurando universos distintos, em que se contrapõem saberes práticos versus saber teórico; permanência e continuidade versus ética do progresso e da inversão para o futuro; afetividade, ternura, sensualidade versus competitividade e êxito intelectual (2003, p. 96-97).

Em consonância com as ponderações da autora, verificamos que os saberes docentes são construídos e reconstruídos nos contextos históricos, sociais e culturais distintos. Tais saberes são constantemente reelaborados pelas professoras alfabetizadoras, de acordo com suas práticas do contexto real e complexo do ensino ao qual estavam inseridas.

As professoras alfabetizadoras de adultos de outrora, assim como cada grupo de educadoras, possuem particularidades de reconhecimento social, imagens complexas que não dependem apenas dos níveis de escolarização, carregam uma imagem social definida, marcante, em que predomina a competência para o ensino das primeiras letras e contas, mas principalmente a benevolência, a dedicação e o zelo com seus alunos. Apesar desses traços promoverem um reconhecimento forte no imaginário social naquela época, contudo não conferia às professoras alfabetizadoras um estatuto profissional. Esse imaginário social ainda possui as marcas das professoras alfabetizadoras, construído há muitas décadas: "Ser professora ou professor é carregar uma imagem socialmente construída. Carregar o outro que resultou de tudo" (ARROYO, 2005, p. 30). Para compreendermos melhor nossa profissionalização, a nós mesmos enquanto educadores e refletir sobre que professor desejamos ou sonhamos ser, não devemos ignorar que o ofício do mestre das primeiras letras, do mestre alfabetizador, permanece no imaginário em que se entrelaçam traços sociais, afetivos, religiosos, culturais, ainda que secularizados. Não podemos esquecer que a ideia de vocação, missão, sacerdócio faz parte da autoimagem das professoras alfabetizadoras e das representações sociais por elas relembradas. Conhecer os mestres, seus saberes, suas práticas, suas histórias de vida é o melhor caminho para compreendermos a escola e o movimento educacional do passado e do presente, estabelecendo ações para o futuro. De acordo com Sacristán, 
meditar sobre o que ocorreu pode dar-nos perspectiva, impulsos e algumas inquietações mobilizadoras [...] Só podemos preencher o "porvir" a partir do presente com projetos, e estes estão enraizados nos ideais do passado e do presente (2000, p. 39).

Para entender o momento educacional atual, é necessário estabelecer um diálogo com os sujeitos da história do magistério, os mestres das escolas, dando-lhes a oportunidade de ocupar a posição de destaque que lhes é de direito. Arroyo (2006) em suas ponderações, esclarece que: "tirando do baú dos esquecidos da história do magistério artes que não deveriam ter sido esquecidas. Artes de ofício. Saberes e sensibilidades aprendidas e cultivadas. Guardadas no cotidiano, nas gavetas das salas de aula de tantos mestres de agora e de outrora" (p. 09).

Nesta categoria, ao construir os saberes das professoras alfabetizadoras entrevistadas, procuramos desnudar a identidade das antigas mestras, compreender o caminho fecundo por onde passaram para, assim, entender a nós mesmos, educadores, um pouco mais. Essa compreensão se deu através do ofício de ser professor, traços e hábitos que todos os mestres repetem, saberes e fazeres que são próprios de sua maestria. Nesta mesma linha de raciocínio Arroyo afirma que:

O termo ofício remete a artífice, remete a um fazer qualificado, profissional. Os ofícios se referem a um coletivo de trabalhadores qualificados, os mestres de um ofício que só eles sabem fazer, que lhes pertence, porque aprenderam seus segredos, seus saberes e suas artes. Uma identidade respeitada, reconhecida socialmente, de traços bem definidos. Os mestres de ofício carregavam o orgulho de sua maestria (2006, p. 18).

O pensar e o fazer educativo moderno originam-se nas artes dos mestres educacionais do passado, no seu saber-fazer, e este sobrevive em nós, educadores e educadoras atuais, que, ao longo da nossa profissão, incorporamos as marcas de um ofício aprendidas e estabelecidas no diálogo de gerações, levando-nos a entender que os saberes específicos da profissão se reproduzem apesar de todas as alterações sofridas na educação e na própria profissão. As professoras alfabetizadoras ao longo de suas vidas foram se constituindo como pessoas e como professoras, na medida em que cada uma, em seus processos de formação com suas experiências de vida pessoal, familiar e profissional foram tomando para si os princípios e valores que produziram um modo de ser e de estar no mundo, ou melhor, um modo de pensar, sentir e agir como pessoas e como professoras. Afirmação interessante é a de Forquin (1992) quando diz que,

a vida é o lugar da educação e a história de vida o terreno no qual se constrói a formação. [...] a análise dos processos de formação, entendidos numa perspectiva de aprendizagem e de mudança, não se pode fazer sem uma referência explícita ao modo como um adulto viveu em situações concretas do seu próprio percurso educativo (p. 167).

O exame das trajetórias de vida das professoras alfabetizadoras que participaram desta investigação possibilitou múltiplas interpretações. Ao ler esse material, encontramos elementos que permitiram desvendar a constituição da subjetividade dessas professoras, como também 
conhecer o conjunto de fatores que contribuiu na formação dos seus saberes. Ao perscrutar a experiência vivenciada pelas professoras alfabetizadoras foi possível compreender/identificar alguns aspectos que historicamente fazem parte da configuração da educação de jovens e adultos no Brasil.

\section{Concepções de Alfabetização e Práticas Pedagógicas}

Constituiu-se em um grande desafio compreender o processo de configuração da educação de jovens e adultos. Para tanto, não se pode perder de vista a análise das trajetórias das professoras alfabetizadoras, cujos percursos de vida estão imbricados com a própria história e origem dessa área. É importante, nesse sentido, respeitar a singularidade dos caminhos percorridos por essas alfabetizadoras, mas também buscar o traço coletivo que entrelaça esses caminhos. Não podemos aprisionar as narrativas em um modelo analítico pré-estabelecido, é preciso permitir a escuta e a aventura da descoberta.

Nessa perspectiva, constatamos que as narrativas das professoras alfabetizadoras se apresenta como um campo aberto para múltiplas possibilidades de leitura e interpretação, pois são diferentes vozes e sentidos que perpassam, permitindo a travessia do relato individual, nomeado e singularizado, para a engenhosa construção do coletivo. Como o narrador descrito por Benjamim (1994), "sua narrativa assemelha-se a sementes guardadas hermeticamente por milênios e que ainda conservam o poder de germinar" (p. 64). Portanto, recolher memórias, registrar vozes e, por meio delas, percursos de vida e de formação, pressupõe revelar as escolhas pessoais, os sonhos, as ideias e as práticas realizadas, conjugando processos de singularização com o traço coletivo que atravessa cada itinerário de vida. A partir dos relatos orais das entrevistadas verificamos a intercessão entre as concepções de alfabetização e as práticas pedagógicas das professoras alfabetizadoras de jovens e adultos. Diante dessa realidade, optamos por analisar em conjunto as categorias alfabetização e práticas, e não de maneira isolada. Também as respostas obtidas a partir das entrevistas foram consideradas de forma coletiva. Retomando a perspectiva das práticas pedagógicas utilizadas no período delimitado neste estudo, ficou evidenciado, por meio dos relatos das professoras alfabetizadoras que, em relação à concepção de alfabetização, especificamente em relação à alfabetização de jovens e adultos, elas concebem como ato de ensinar a ler e escrever e, em alguns casos, reduzindo ao ato de aprender a assinar o próprio nome.

Ao indagar as professoras alfabetizadoras a respeito da concepção de alfabetização, percebemos que em vários momentos, ao falarem de suas práticas pedagógicas, as entrevistadas pautavam suas respostas a partir da vivência cotidiana, da elevação da autoestima, do ensino de artesanato e de práticas culinárias. É essencial, para a qualidade do processo de ensino em turmas de jovens e adultos, que os educadores atentem para o bom relacionamento com seus educandos, pautado no respeito à realidade existente, ao modo como pensam, sentem e agem, procurando adequar suas práticas à forma diferenciada de que necessitam. Essa confiança desenvolvida entre educador e educando torna-se essencial no processo de ensino, acarretando o desbloqueio emocional do educando em relação à sua capacidade de aprender. Muitas vezes, ao se desconsiderar a realidade dos alunos adultos, o professor alfabetizador incorre no risco de estabelecer uma relação entre capacidade intelectual e analfabetismo, associando a condição de analfabeto a déficits individuais, e não a questões de desigualdades sociais. Assim, um problema que é eminentemente social se torna individual. 
Os relatos das professoras alfabetizadoras sobre a prática pedagógica apresentaram alguns pontos convergentes. O principal deles foi a falta de planejamento e o exercício solitário da docência, no qual fica evidente a precariedade em que a educação de jovens e adultos era oferecida. Como destacado anteriormente, algumas das entrevistadas exerceram a função de alfabetizadora de jovens e adultos na condição de leigas, pois somente concluíram o magistério depois de algum tempo de atuação, e mesmo assim, exerceram a profissão sem apoio pedagógico, sem acompanhamento e sem planejamento. Fica claro que esta situação angustiava as professoras, que ansiavam por maior acompanhamento. Acrescido a precária formação para o exercício da docência, a falta de planejamento, o trabalho solitário e pouco compartilhado, na fala das educadoras ainda é possível perceber as dificuldades com a infraestrutura das escolas, bem como a falta ou inexistência de material didático pedagógico para o trabalho com a alfabetização de jovens e adultos.

É recorrente nos relatos das entrevistadas a alegação de que exerciam a docência em locais pouco apropriados, muitas vezes improvisados e basicamente utilizando a lousa e o giz. Quando afirmam que recebiam algum tipo de material avaliam que ou eram distantes da realidade, porque já vinham prontos de algum órgão educacional, ou eram mais apropriados para o trabalho com as crianças. Nesse aspecto as ponderações de Arroyo (2006) remetem à questão da infantilização do ensino de adultos, "devemos, nesse momento, ser capazes de inventar uma pedagogia da educação de adultos, construindo o pensamento pedagógico além da pedagogia infantil" (p. 89). Segundo esse pesquisador, ainda não temos no país nem um perfil de educador de jovens e adultos, nem um parâmetro de formação desses educadores. $\mathrm{O}$ perfil deste é plural e o processo é truncado, demonstrando que a EJA tem circulado mais entre os projetos de emancipação da sociedade que entre os projetos de educação.

Ao relatarem suas práticas pedagógicas, as entrevistadas nem sempre associavam as precariedades destacadas acima às dificuldades de aprendizagem de seus alunos, pois, segundo elas, os alunos não mediam esforços para aprenderem, eram dedicados e cumpridores de seus deveres. Dessa forma, ainda que as adversidades se apresentassem como empecilho, as professoras alfabetizadoras não se deixavam abater, procuravam valorizar o interesse dos educandos. Quando descreveram essas práticas pedagógicas, se concentraram na dimensão afetiva que mantinham com seus alunos e com a docência, em detrimento da metodologia que utilizavam. Percebemos que de maneira geral elas apresentaram um saudosismo em relação à escola, à educação e aos alunos da época em que foram professoras alfabetizadoras de jovens e adultos. Apesar de destacarem as dificuldades, a pouca ou quase nenhuma condição de trabalho, elas acreditavam que a educação era melhor do que hoje, mesmo quando afirmavam que atualmente as escolas possuem muito mais materiais e uma infraestrutura melhor. Também consideravam que tanto o ensino, quanto os alunos eram melhores. Conforme asseveraram o aluno do passado respeitava o professor, era "disciplinado" "obediente", pacato e educado, sendo esse o aluno ideal. As professoras não se reportaram ao aprendizado dos seus alunos, mas ao comportamento que eles apresentavam em sala de aula, isso se justifica pelas representações que tinham sobre a educação. Assim sendo, ao nosso ver, as entrevistadas não concebem o processo ensino-aprendizagem, tal qual é idealizado na atualidade, por esse motivo ao relembrarem a prática docente efetivada não fizeram com base em pressupostos educacionais e sim com base em condutas comportamentais. 
Verificamos nos relatos das professoras alfabetizadoras que quando o foco da prática pedagógica era direcionado para o professor e não para o aluno, elas também demonstravam saudosismo. As suas considerações tiveram por base a relação afetiva, a relação professoraluno-família-sociedade, confirmado aquilo que já ponderamos anteriormente em relação ao oficio de ser professor como uma missão, um sacerdócio. Elas retratam em suas falas uma concepção de educação em que o ensino estava imbricado à ideia de respeito, de afeição tanto pelos alunos, como pela própria sociedade.

Além de se concentrarem no respeito que tinham por parte dos alunos e da sociedade pautaram seu relato também na relação afetiva entre elas e a docência. Toda dificuldade, precariedade, obstáculos que vivenciaram como professoras da educação de jovens e adultos parece que deixaram marcas menos profundas do que a relação de afeto com a profissão.

Ao discorrerem sobre a relação ensino-aprendizagem, conferimos que há uma grande concentração nas atividades de leitura e escrita, como ditado, leitura individual, cópia etc. Aparece também, de forma secundária, o trabalho com matemática, sempre associado às atividades de adição, subtração, divisão e multiplicação, aludidas pelas professoras como o trabalho com "as contas".

De uma maneira geral as professoras entrevistadas apresentaram uma visão singular da educação de jovens e adultos, em muitos momentos dos relatos descrevem as situações vividas. Além de toda a precariedade colocada por elas, como falta de planejamento, de material didático pedagógico, infraestrutura deficiente, etc., pontuam outros aspectos que mereceriam uma análise crítica como, por exemplo, as condições vividas pelos alunos. As professoras relataram que eles vinham cansados, sem banho, sem alimentação. Relataram também a carga horária, sendo, em muitos casos de apenas duas horas diárias, mas não dão indício de que consideravam que estes pontos poderiam influenciar o processo ensino-aprendizagem.

\section{Considerações Finais}

Reconstruir a memória e a história de professoras alfabetizadoras de jovens e adultos, entre o período de 1940 a 1960, constituiu-se o principal objetivo desta pesquisa. Assim, uma questão primordial desta investigação foi entender o que significava ser professora alfabetizadora da EJA, naquele período (1940-1960). Na tentativa de encontrar resposta para o questionamento proposto, surgiram algumas inquietações, e com o intuito de subsidiar a questão fundante, busquei identificar quem foram as professoras que atuaram no processo de alfabetização de jovens e adultos? Em que lugares alfabetizaram e em que condições? O que as levou à profissão? Que concepções teórico-práticas construíram em torno do ato de ensinar e aprender? Estas questões se destacaram exatamente por serem as mais pertinentes e indicativas do que foi ser professora alfabetizadora na década de 1940-1960, no Norte de Minas Gerais.

Nesse sentido, a partir das narrativas das professoras alfabetizadoras como testemunhas de um tempo vivido, dos documentos encontrados e das referências sobre o assunto, foi possível entender a documentação escrita e tecer a trama que se processou em torno dessas profissionais, quanto aos princípios da alfabetização de jovens e adultos. As narrativas, os documentos e as referências se constituíram em fontes importantes para que pudéssemos perceber o pensar, o sentir e o agir de sete professoras alfabetizadoras, que se transformaram em protagonistas na construção de um ideal de educação, com a missão de instruir e educar o povo analfabeto. 
Dentro das especificidades locais, este estudo contribuiu para ampliar a compreensão dos processos educacionais da cidade de Montes Claros- MG, demonstrando as conexões existentes entre a história local, regional e nacional e conferindo visibilidade às professoras alfabetizadoras de jovens e adultos, convocadas, para cumprir tão importante missão.

Essa história se desenvolveu em um período marcado por muitas transformações sociais, políticas e econômicas na sociedade brasileira e refletiu, de forma contundente na educação, estimulando propostas de reformas institucionais voltadas para a erradicação do analfabetismo. Nessa perspectiva, a educação tornou-se responsável pelas mudanças que deveriam acontecer no país, para construir a nação e configurou-se de maneira mais doutrinária, com caráter autoritário e nacionalista no período do governo do Estado Novo.

Para tanto, utilizamos a história oral que é a mais apropriada para esse tipo de pesquisa. Tendo por base os apontamentos teóricos que subsidiaram este trabalho reportamos a Magda Soares (2003) quando utilizando da fala de Fontana pondera que o processo em que alguém se torna professor é histórico, portanto, "os indivíduos que se fizeram professores vão se apropriando das vivências práticas e intelectuais, de valores éticos e das normas que regem o cotidiano educativo" (p. 48) para constituir seu ser professor, não sendo esta construção desarticulada do momento histórico-social. Portanto, ser professora alfabetizadora no momento histórico e no espaço geográfico escolhido para esta pesquisa, está intrinsecamente associado às vivências tanto educativas, como sociais, políticas, familiares das professoras alfabetizadoras.

Como pano de fundo, as vivências das professoras investigadas constituíram seu fazer docente, que não diferente da maior parte das experiências brasileiras de alfabetização de jovens e adultos, se distanciou da perspectiva apresentada por Freire (1967), quando sugere que a prática da alfabetização de adultos deveria ter por base o mundo social e cultural dos educandos, formando sujeitos críticos capazes de transformar o mundo. Esse distanciamento dos pressupostos de Freire não é intencional, nem representou falta de compromisso profissional e social das professoras alfabetizadoras, simplesmente demonstrou a força das conjunturas políticas, sociais e educacionais na construção dos saberes e das práticas educativas daquele momento. Nas narrativas das entrevistadas, em várias passagens de suas lembranças podemos perceber o compromisso, a entrega e a dedicação ao exercício da docência. No entanto, essa dedicação não se apresentou como suficiente para romper com mazelas que sempre estiveram presentes na educação e especialmente na educação de jovens e adultos no nosso país.

Em alguns momentos, apreendemos que as professoras impregnaram ao seu fazer docente a visão do magistério como sacerdócio, como abnegação. Mesmo ao relatarem as precárias condições profissionais, inclusive o exercício do magistério sem o recebimento do salário, fizeram com forte carga emocional, enfatizando a importância da "missão" de alfabetizar os jovens e adultos. Entendemos esta postura, pois ela representa uma concepção de alfabetização e de prática docente para jovens e adultos que fora vislumbrada por essas educadoras. O momento histórico, as conjunturas locais, as condições de formação docente foram determinantes para a permanência e a consolidação desta visão do magistério como sacerdócio e da visão restrita da alfabetização de jovens e adultos, distante dos pressupostos de Freire, como destacado acima. Como afirma Fontana (2003), esposa, filha, mãe e professora se entrelaçam nos moldes de ser e de dizer de cada professora. 
O respeito e a valorização da postura apresentada pelas professoras entrevistadas não impedem de ressaltar que esta visão do magistério como sacerdócio e da alfabetização apenas como aquisição do código escrito, sem a visão ampla que Freire propõe, de cunho mais político, ou a visão da alfabetização associado ao letramento, perspectiva de cunho mais educacional defendida por Magda Soares, bem como por Kleimam (2000), ajudaram na permanência de muitos dos desafios da educação de jovens e adultos. Reportando novamente ao referencial teórico que embasa este trabalho, pautamos em Gadotti (2014) quando ele destaca dois motivos que justificam a permanência do analfabetismo no Brasil. $\mathrm{O}$ autor aponta que muitos alunos saem semianalfabetos da escola, gerando novos analfabetos e que a escola não acolhe de maneira coerente e justa os alunos oriundos da EJA, não possibilitando a ampliação do processo de escolarização e de acesso ao conhecimento. Também buscamos embasamento nas considerações de Miranda (1991), a qual ressalta que a escola precisa se perguntar em que medida suas concepções de alfabetização, e acrescentamos de alfabetização de jovens e adultos, têm contribuído para a manutenção ou a transformação do que está posto.

As alfabetizadoras entrevistadas exerceram sua profissão em condições precárias, tanto de infraestrutura, como de recursos matérias, trabalharam em uma localidade e em uma época fortemente marcada pela interferência política nas decisões educacionais, trabalharam com pouco ou quase nenhum aporte didático-metodológico, principalmente se levarmos em consideração a adequação destes aportes para o alunado atendido na educação de jovens e adultos, mas mesmo assim apresentaram uma visão muito positiva do trabalho realizado.

A vinculação entre ação docente e amor à profissão é bem forte nos relatos das professoras e, confessamos, sensibilizou-nos. Mas também propiciou refletir até que ponto contribuiu para a visão presente de que é possível fazer educação e, principalmente educação de jovens e adultos com pouco recurso, em condições adversas, com profissionais pouco preparados, com material pouco adequado. Quando se defende que a ação docente se faz a partir das vivências dos educadores e que esta vivência está fortemente marcada pelos valores do cotidiano, perguntamo-nos se muito das vivências das professoras alfabetizadoras que participaram desta pesquisa não se assemelham às vivências dos professores de hoje, que militam na EJA; e se os valores e concepções de alfabetização de jovens e adultos de hoje ainda não mantém sintonia com os da década de 1940-1960, época em que as entrevistadas exerceram o oficio da docência.

Este ponto demonstra a importância em lutar para transformar as conjunturas que provocam situações de desigualdade, que no caso deste trabalho se trata da desigualdade de condições sociais e educacionais que provocam o analfabetismo. Muito se modificou da década de 1940-1960 para os dias de hoje, mas muita coisa também se manteve. Podemos apontar como importantes mudanças a melhoria na qualificação dos professores, melhoria na infraestrutura das escolas, maior aporte didático-pedagógico para o desenvolvimento das atividades docentes, etc. Todavia, podemos apontar algumas permanências que impactam negativamente a educação de jovens e adultos. Em uma visão macro, podemos apontar a ainda enorme desigualdade social do nosso país que continua excluindo jovens do sistema educacional, a má qualidade do ensino, principalmente o destinado à população em situação de maior vulnerabilidade social, entre outros. Em uma visão mais focada no ambiente educacional, podemos apontar a manutenção da educação de jovens e adultos em uma posição secundária em relação a outras modalidades de ensino. 
Avaliamos que, nos dias atuais, essa modalidade de ensino não tem o status, tampouco as mesmas condições da educação regular. Ao reportar os muitos impasses vivenciados pelas professoras alfabetizadoras entrevistadas nesta pesquisa, apreendemos que, guardadas as devidas proporções, esses ainda estão presentes na EJA. Não se pode negar que nos últimos anos algumas universidades públicas têm desempenhado um importante papel na formação docente para essa modalidade, contribuindo com experiências enriquecedoras e despertando a academia para essa problemática. Contudo, muitas ainda não têm assumido a EJA como parte integrante de suas políticas e ações. A ausência de disciplinas ou habilitações específicas de educação de jovens e adultos nos cursos de formação inicial de nível médio e superior apresentam-se como obstáculo para o despertar e/ou aprofundamento das reflexões sobre as diversas dimensões que constituem essa modalidade educativa. Conforme, Fávero e Rumert, (1999), a ausência de preocupação com a formação de professores da EJA possui raízes históricas e relaciona-se a um conjunto de representações arraigadas na cultura que perpassa a educação e outras práticas sociais.

Essas representações podem ser percebidas em muitas práticas da EJA, as quais são associadas ou mesmo reproduzidas a partir de práticas desenvolvidas para a educação infantil, como se o jovem e o adulto, com pouca ou nenhuma escolarização, fosse um aluno que simplesmente deixou de cumprir, por deficiências próprias, a tarefa que lhe cabia na infância, ou seja, estudar. Em decorrência disso, as práticas pedagógicas da EJA são infantilizadas e os alunos jovens e adultos, em certa medida, tratados como "crianças grandes", "marmanjos" que não aprenderam na "idade apropriada".

Finalizamos este trabalho na certeza de que as sete professoras alfabetizadoras de jovens e adultos selecionadas para este estudo, mesmo tendo exercido a docência nas conjunturas já destacadas, com as trajetórias pessoais e profissionais que a época (19401960) possibilitava, e ainda que tivessem o magistério como sacerdócio, demonstraram um razoável entendimento da EJA. Fazemos esta afirmativa por verificar que no momento de seus relatos destacaram pontos cruciais para a garantia de uma alfabetização de jovens e adultos com responsabilidade e compromisso.

Quando demarcaram como ponto positivo a valorização que o professor tinha na época, mesmo sem fazer uma análise de que essa valorização deveria estar atrelada a condições dignas de trabalho, elas indicaram a importância desse fato. Ao relatarem a falta de materiais didáticos pedagógicos específicos para a faixa etária dos alunos da EJA, demonstraram o quanto seria importante que os tivesse. A alegação de que exerciam a docência de maneira solitária, sem acompanhamento e com pouco planejamento, aponta como elas consideravam imprescindível realizar o seu trabalho de forma coletiva, planejada e apoiada em bases pedagógicas. Ao referendar a postura de seus alunos jovens e adultos, exaltando o comportamento obediente, educado e responsável, demonstram claramente reconhecer a necessidade de se tratar com distinção esses educandos e que a boa relação professor-aluno é fundamental para a efetivação de um bom trabalho.

Ainda que os trabalhos acadêmicos exijam do pesquisador um afastamento do seu objeto de pesquisa, prevenindo um possível envolvimento emocional, todos esses apontamentos falam alto e não nos deixam alheios ao que representou, na vida daquelas mulheres, o ser professora. Talvez, passe por aquele pensamento sublimado de sacerdócio, de missão, de maternidade, 
entretanto, acreditamos que passa, muito mais, pelo compromisso, competência, dedicação, entre outros atributos, de quem deseja propiciar ao educando, jovem e adulto, o reconhecimento de sua dignidade, de sua capacidade de reverter a sua história, de fazer um novo caminhar, de ter garantidos os seus direitos, a sua cidadania.

Numa sociedade em que tantas desigualdades imperam, e que os preconceitos, por mais que combatidos, insistem em permanecer, há que se pensar numa educação de jovens e adultos que possibilite um novo jeito de ser e estar no mundo, uma educação que seja de fato direcionada a esses alunos e que considere a sua realidade.

\section{Referências}

ALMEIDA, Paulo Roberto de. \& KHOURY, Yara Aun. (orgs.) Outras Histórias: Memórias e Linguagens. São Paulo: Olho D’Água, 2006.

ARAUJO, José Carlos Souza, RIBEIRO, Betania de Oliveira Laterza, SOUZA, Sauloéber Társio de. Haveria uma historiografia educacional brasileira expressa pelos manuais didáticos publicados entre 1914 e 1972? IN: CARVALHO, Marta Maria Chagas de, JUNIOR, Décio Gatti (Org). O Ensino de História da Educação. Vitória: EDUFES, 2011.

ARROYO, Miguel G.Formar Educadores e Educadoras de Jovens e Adultos. In. Soares, Leôncio (org.) Formação de Educadores da Educação de Jovens e Adultos. Belo Horizonte: Autêntica, UNESCO/ MEC, 2006.

ARROYO, Miguel G. Educação de jovens-adultos: um campo de direitos e de responsabilidade pública. In: SOARES, Leôncio; GIOVANETTI, Maria Amélia G. C. GOMES, LINO, Nilma. (orgs.). Diálogos na educação de jovens e adultos. Belo Horizonte: Autêntica, 2005. p. 19- 50.

BARROS, José D’Assunção. O campo da história: especialidades e abordagens. Petrópolis: Vozes, 2005.

BASTOS, Maria Helena Câmara. Novos temas em história da educação brasileira: instituições escolares e educação na imprensa. IN: ARAUJO, José Carlos Souza, JUNIOR, Décio Gatti (Org). - Campinas: Autores Associados; Uberlândia, MG; Edufu, 2002.

BEnjamin, W. Magia e Técnica, Arte e Política: Ensaios sobre Literatura e História da Cultura. Obras Escolhidas. Volume I. 5. Ed. Tradução de Sérgio Paulo Rouanet. São Paulo: Brasiliense, 1994.

BOSI, Ecléa. Memória e sociedade: Lembranças de velhos. São Paulo: Cia das Letras, 2004.

CAVALCANTE JUNIOR, Idelmar Gomes.; SILVA, Maria do Rosário de Fátima Vieira da.; COSTA, Rozane da Silva. A história cultural de Gilberto Freyre e SérgioBuarque de Hollanda e os novos rumos da historiografia brasileira. RevistaF@pciência. v.6, n. 6, p. 47-54, 2010. Disponível em: <http://www.fap.com.br/fapciencia/006/edicao_2010/006.pdf〉. Acesso em: 25 out. 2013. 
FÁVERO, Osmar; RUMERT, S. Formação de profissionais para a educação de jovens e adultos trabalhadores. Educação em Revista. n. ${ }^{\circ}$ 30, Belo Horizonte: FAE/UFMG, 1999.

FONTANA, Roseli A. C. Como nos tornamos professoras? Belo Horizonte: Autêntica, 2003.

FORQUIN, Jean-Claude. Saberes escolares, imperativos didáticos e dinâmicas sociais. Teoria e Educação. n.5. Porto Alegre, 1992.

FREIRE, Paulo. Pedagogia do Oprimido. Rio de Janeiro, Ed. Paz e Terra, 1987.

GADOTTI, Moacir. Por uma Política Nacional de educação popular de jovens e adultos. São Paulo: Moderna. Fundação Santillana, 2014.

GERVAISE, Yves. A transformação agrária do Nordeste Meridional (Norte de Minas Gerais). Belo Horizonte: UFMG, 1975.

HALBWACHS, Maurice. A Memória Coletiva. São Paulo: Ed. Centauro, 2004, p.91.

HOBSBAWM, Eric. Sobre História. São Paulo: Companhia das Letras, 1998.

INÁCIO FILHO, Geraldo e ABREU Vanessa Kern de. A educação moral e cívica - doutrina, disciplina e prática educativa. Revista HISTEDBR On-line, Campinas, n.24, p. 125 -134, dez. 2006 - ISSN: 1676-2584.

KLEIMAN, A.B..O processo de aculturação pela escrita: ensino da forma ou aprendizagem da função? In: KLEIMAN, A.B; SIGNORINI, I. (orgs.). O ensino e a formação do professor: alfabetização de jovens e adultos. Porto Alegre: Artmed, 2000, páginas 102-106.

LE GOFF, Jacques. Historia e memória. São Paulo: Editora da Unicamp, 2003.

MEIHY, José Carlos Sebe B., HOLANDA, Fabíola. História Oral: como fazer, como pensar. $2^{a}$ ed. São Paulo: Contexto, 2010.

MIRANDA, Marildes Marinho. Os usos sociais da escrita no cotidiano de camadas populares. Dissertação (mestrado em Educação). Faculdade de Educação, UFMG, Belo Horizonte, 1991.

NETO, Wenceslau Gonçalves. Novos temas em história da educação brasileira: instituições escolares e educação na imprensa. IN: ARAUJO, José Carlos Souza, JUNIOR, Décio Gatti (Org). Campinas: Autores Associados; Uberlândia, MG; Edufu, 2002.

NÓVOA, Antônio. A imprensa de educação e ensino: concepção e organização do repertório português. In: CATANI, D. B.; BASTOS, M. H. C. (Org.). Educação em revista. A imprensa periódica e a história da educação. São Paulo: Escrituras, 1997, p. 30-31-221 
SANTOS, Sônia Maria. Histórias de Alfabetizadoras Brasileiras entre saberes e práticas. Tese (Doutorado em Educação) - Pontifícia Universidade Católica, São Paulo, 2001.

PEREIRA, Anete Marilia. Cidade Média e Região: O Significado de Montes Claros no Norte de Minas Gerais. (tese doutorado): Universidade de Uberlândia- UFU. Uberlândia, 2007.

PEREIRA, Laurindo Mékie. A Cidade do Favor: Montes Claros em meados do século XX. Ed. Unimontes. Montes Claros, 2002.

PESAVENTO, Sandra Jatahy. História e historia cultural. Belo Horizonte: Autêntica. 2003.

PORTELLI, Alessandro. Tentando aprender um pouquinho. Algumas reflexões sobre a ética em História Oral. São Paulo: Projeto História nº 15, abr.1997.

PORTELLI, Alessandro. Ensaios de História Oral. São Paulo: Letra e Voz, 2010. RIBEIRO, Eduardo M. (org.) História dos gerais. Belo Horizonte: UFMG, 2011.

SACRISTÁN, J. Gimeno. O Currículo: Uma Reflexão Sobre a Prática. $3^{\mathrm{a}}$ ed. Porto Alegre: Artmed, 2000.

SOARES, Magda. B. Letramento: Um Tema em três gêneros. Belo Horizonte, Autêntica, 2003.

SOUZA, Rosa Fátima de. Um itinerário de pesquisa sobre a cultura escolar. In: CUNHA, Marcos Vinicius da (org.). Ideário e imagens da educação escolar. Campinas: Editora e Autores Associados, 2000.

THOMPSON, Paul. HISTÓRIA ORAL: Revista da Associação Brasileira de História Oral, n.5, jun.2002. - São Paulo: Associação Brasileira de História Oral. V.5.

VELOSO, Geisa M. A missão "desanalfabetizadora" do Jornal Gazeta do Norte, em Montes Claros. (1918-1938) Tese de Doutorado/UFMG, 2008. 